\title{
Multivariate Approaches to Measure the Association among Socio-Economic and Demographic Factors of the Farm Households in West Bengal, India
}

\author{
G. Samba Siva*, D.S. Gupta and Debobrata Ghosh \\ Department of Agricultural Statistics, Uttar Banga Krishi Viswavidyalaya, \\ Cooch Behar, West Bengal-736 165, India \\ *Corresponding author
}

\section{A B S T R A C T}

\section{Keywords \\ Exploratory Factor Analysis (EFA), \\ Canonical \\ Correlation \\ Analysis (CCA), \\ socio economic and \\ demographic \\ characteristics of \\ farm households \\ Article Info \\ Accepted: \\ 12 May 2019 \\ Available Online: \\ 10 June 2019}

The study aimed to identify the social and demographic factors affecting the economic status of farm households in West Bengal. The results of multivariate approaches like Exploratory Factor Analysis revealed that household size, age group, farm size, gender, labour force participation rate, occupation and education were identified as key variables based on the highest factor loadings of each factor. The canonical correlation analysis based on these key variables yielded function 1 and function 2 with squared canonical correlations $\left(R_{c}^{2}\right)$ of 0.288 and 0.088 for each successive function and revealed that farm size $\left(r_{s}=0.837 ; r_{s}^{2}=70.06\right)$, household size $\left(r_{s}=0.637 ; r_{s}^{2}=40.58\right)$ and education $\left(r_{s}=0.457 ; r_{s}^{2}=20.88\right)$ showed significant influence on family income levels $\left(r_{s}=0.813 ; r_{s}^{2}=66.10\right)$ which resulted in improved in socioeconomic status of farmers.

\section{Introduction}

A demographic base becomes more relevant to have a comprehensive profile of the farm households. The social and demographic factors viz. age, sex, education, occupation, household size, labour force participation rate $(\%)$, land holding size, etc. helps in assessing the economic status of the rural farmers and in turn reflects the social condition of the farm households (Oloruntoba and Fakoya,
2000). The farm size is a strong determinant of the expected output yield in adoption of improved technologies by the farmers (Onumadu and Osahon, 2014) and the preponderance of marginal and small farmers is crucial for assessment of the farmers' condition.

The effect of socio economic factors on adoption of improved agricultural practices by the farmers in farming enterprises were 
measured and identified significant positive relationship between farm size, labour use pattern, education, occupation and annual income of the farmers (Singha et al., 2012; Krishna, 2012; Ven, 2013; Adegboye, 2016). The demographic factor, family size had a direct influence on the expenditure and income patterns of the family (Dey et al., 2014).

The socio-economic attributes of farmers viz, family size, education level, farming experience and size of landholding, livestock numbers, farmers' age have positive influence on farm income and are strongly related to farming success. Moreover, socio-economic attributes vary geographically; the relationships may also vary spatially (Samaun Safa, 2005). Education is considered as one of the effective social condition of farm households. It enhances the ability of the farmers to work with production inputs and their disposal to produce more output with fewer inputs. Moreover, the adopters who are better educated enjoyed better economic status and have active social participation (Chand and Gupta, 1966).

\section{Materials and Methods}

The State of West Bengal is situated in eastern part of the country between $21^{\circ} 25^{\prime} 24^{\prime \prime}$ and $27^{\circ} 13^{\prime} 15^{\prime \prime} \mathrm{N}$ latitude and $85^{\circ} 48^{\prime} 20^{\prime \prime}$ and $89^{\circ}$ 53' 04" E longitude, respectively. West Bengal is predominantly an agrarian state having a geographical area of about 88,752 sq. $\mathrm{km} .(2.7 \%$ of the India's total geographical area). As per the 2011 census, the state of West Bengal houses 71.23 lakh farm families, out of which 96 per cent are small and marginal farmers. The average size of farm holding in the state is nearly 0.77 ha. The farm cultivators and agricultural labourers constitute 20.56 per cent and 40.8 per cent of the total rural workers respectively. However, the State is bestowed with varied agro- climatic conditions and diverse natural resources suitable for cultivation of wide range of crops.

The data collected by "Comprehensive Scheme for Studying Cost of Cultivation or Production of Principal crops (CCPC)" in India through three-stage stratified PPSWR followed by stratified WOR sampling design (GOI, 1980) over the period from 2008-11 in West Bengal has been utilized for the present study. Descriptive statistics (frequency distribution, mean, standard deviation, minimum, maximum), multivariate approaches like Exploratory Factor Analysis and Canonical Correlation Analysis were performed in this study.

Exploratory factor analysis is a multivariate statistical technique of data exploration to determine the structure of factors to be analyzed and commonly employed in information systems, social sciences, education and psychology etc. (Williams and Brown, 2010). One of the major uses of factor analysis is to summarize the data without losing any important information thereby making it easier to test theories (Tabachnick and Fidell, 2007). The principal component method is the most commonly used method of extraction in factor analysis (Kinnear and Gray, 2010) used by Statistical Package for the Social Science (SPSS 17.0). An advantage of factor analysis is that it reduces the measurement problems, such as recall bias and complexity of correlated data, which can be easily collected as single indicator variables in household surveys (Yvas, 2006). The factors with eigenvalues more than one were used as the key variables which describe sufficiently the socio economic status of farm households.

The principal component matrix indicates the component matrix which is rotated using varimax rotation technique, which further 
provides the rotated component matrix. Rotation of factors helps in better interpretation of factors. The communalities obtained for the socio economic and demographic factors of the farm households were relatively large (greater than 0.5 ), hence, the data set was appropriate for further analysis (Stewart, 1981).

Another multivariate statistical techniques used in this study was Canonical Correlation Analysis (CCA). The canonical correlation $\left(R_{c}\right)$ depicts the strength of the correlation between pairs of synthetic (or latent) scores based on the original variables. These synthetic scores are arrived by the formation of linear composites based on weighting of the original variables (see Thompson, 1991 or Hotelling, 1935 for further details). The main idea of CCA is to determine the pair of linear combinations having the highest correlation first. Next, we determine the pair of linear combinations having the largest correlation among all other pairs uncorrelated with the initially selected pair, and so on. The pairs of linear combinations were called the canonical variables, and their correlations were named canonical correlations. The variable relationships in a hypothetical CCA with four predictor and two criterion variables were illustrated in Figure 1.

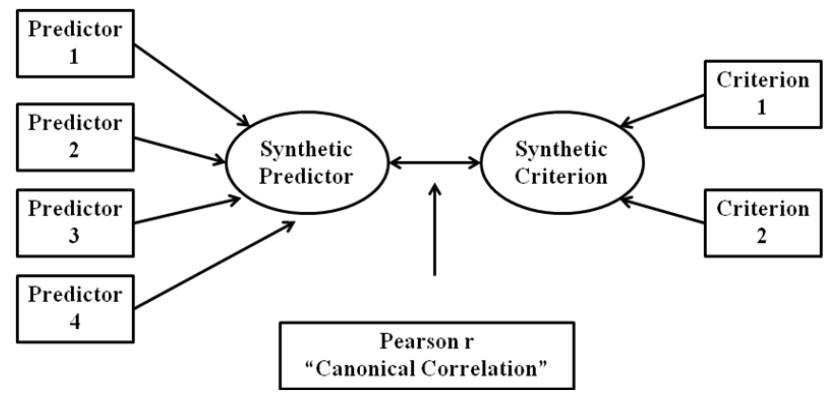

Figure.1 The canonical correlation is the simple Pearson $r$ between the two synthetic variables, which were linearly combined from the observed variables

Important Canonical Correlation Analysis (CCA) terms viz. canonical correlation coefficient $\left(\mathrm{R}_{\mathrm{c}}\right)$, squared canonical correlation $\left(R_{c}^{2}\right)$, canonical function or variate, Standardized canonical function coefficients, structure coefficient $\left(r_{s}\right)$, Squared canonical structure coefficients $\left(r_{s}^{r^{2}}\right)$ and canonical communality coefficient $\left(h^{2}\right)$ help to understand the CCA results in later sections (see Sherry and Henson, 2005 for further details). The detailed statistical procedures given by Johnson and Wichern (2007) were followed in the present study.

\section{Results and Discussion}

\section{Socio economic and demographic characteristics of the farm households}

Study on the social and the demographic features help to understand the attitude of the farmers on adoption of modern production technologies and also on the proper utilization of other non-labour inputs. Likewise, a study on the economic conditions of the farmers also helps in understanding the investment behavior of agriculturists on crop production.

The summary statistics of the study (Tables 1 and 2) indicate that the farm households in West Bengal state are dominated with males $(53.08 \%)$ and a mean age of the farmer is 49 years. The age of the household head is an important factor as it determines whether the household is benefited from the experience of older farmers or the risk taking attitude of young farmers. The farming households in this study were medium sized families $(52.33 \%)$ with an average household size of six members, out of which four members are prime adults, i.e. age between 15 and 59 years. The head of household involved in 77 per cent of farm work, where as the household members involved in only 23 per cent of farm work.

Majority of the farmers were small farmers with an average land holding size of 1.5 
hectares having crop production as major occupation. With regards to education, majority of them have secondary level of education and two to three members were involved in earning money for their family. Family Education Score was calculated simply by multiplying respective number of household members in a family with their level of education. The average annual family net income was Rs. 42,729 and an average capital available for crop production was Rs. 23,008 per annum. The average labour force participation rate from the farm household was 41 per cent. $\operatorname{LFPR}(\%)$ determines the level of socio economic development and the work force participation indicates the number of eligible labour available in the farm households and is calculated by using the formula (Suri and Chhabra, 2009).

Labour Force Participation Rate $(\%)=\frac{\text { Number of working population }}{\text { Total population }} X 100 \ldots \ldots$.... (1)

Relationship between socio economic and demographic characteristics of the farm households

The study aimed to examine the interrelationship between socio-demographic and economic characteristics of the farm households i.e. how economic status was influenced by socio demographic characteristics of the farm households. Exploratory Factor Analysis (EFA) was applied to those socio demographic indicator variables (As mentioned in Table 1 and 2) to determine the important factors considered for estimating the socio economic status of the farmers in West Bengal. The result of EFA based on varimax rotation component matrix (Table 3) demonstrated that first seven factors had eigen values weight greater than one and explained 76 per cent of the total variability of the original variables and thus suited to represent the socioeconomic status of the farm households in further analysis. The varimax rotated component matrix clearly demonstrated the maximum part of variance in Factor 1 was explained by a linear combination of variables viz. household size (0.976), family size (0.904), number of females (0.852), number of males (0.843), number of adults (0.811), family education (0.731), number of children (0.586) and number of youth persons (0.559). Similarly, linear combination of variables like farm size (0.874) and land category (0.864) in Factor 2; linear combination of variables like LFPR (0.834), work on farm by family (0.637), number of earners (0.629) and family members involved in crop production $(0.570)$ in Factor 3; linear combination of variables like farmer's age group (0.944) and actual age (0.935) of the farmers in Factor 4; linear combination of variables like farmers occupation (0.820), family members involved in non-crop production (0.722) and work on farm by farmers $(-0.726)$ in Factor 5; linear combination of variables like gender $(0.851)$ and marital status (0.725) in Factor 6 and linear combination of variables like education of the farmers (0.742) and number of old aged persons in the family $(0.726)$ in factor 7 explained the maximum variability in each respective factors.

The loadings of each variable on each of the extracted factor have shown by the rotated component matrix. The objective of this matrix was to find variables which have high loadings on one factor, but low loading on other factors. The first factor in the rotated component matrix was observed to be heavily loaded with household size and having a factor loading value of 0.976 which was observed to be the highest. Hence, household size represents the first factor. Since the second factor was observed to be heavily loaded with farm size (0.874), the factor two represents farm size. Subsequently other factors could be interpreted based on their respective Eigen values. The final list of 
seven variables which collectively accounted for 76 per cent of total variance was enlisted in Table 4.

Canonical correlation analysis was done by using seven socio demographic variables identified based on Exploratory Factor Analysis (Shown in Table 4) as predictor set and the two socio economic variables viz. annual family net income and capital available for crop production as dependent set to evaluate the multivariate shared relationship between socio economic and demographic variable sets. The analysis identified function 1 and function 2 with squared canonical correlations $\left(R_{c}^{2}\right)$ of 0.288 and 0.088, respectively. Assumption regarding the multivariate normality were met for the full model across all functions was statistically significant by using the Wilk's $\lambda$ $=0.649$ criterion, $F(14,1182)=20.304, \mathrm{p}<$ 0.0001 (Table 5). Where, Wilk's $\lambda$ represents the variance unexplained by the model and the full model effect size in an $r^{2}$ metric was yielded by $1-\lambda$. Thus, for the set of two canonical functions, the $\mathrm{r}^{2}$ type effect size was 0.351 , which indicates that the full model explained a substantial portion of nearly 35 per cent of the total variance was shared between the two variable sets.

The dimension reduction analysis allows the researcher to test the hierarchal arrangement of canonical functions (a set of standardized canonical function coefficients for the observed predictor and criterion variable sets) from statistical significance. As noted, the full model (Functions 1 to 2) was statistically significant and the functions 2 to 2 was also significant, $F(6,592)=9.519, \mathrm{p}<0.0001$. Given, the $R_{c}^{2}$ effects which represent the proportion of variance shared by the two synthetic variables and for each function, only the first function was considered noteworthy in the context of this study $(28.8 \%)$, while the second function explained only 8.8 per cent of the remaining variance in the variables set after the extraction of the prior functions (Table 6).

The standardized canonical function coefficients, structure coefficients, squared structure coefficients as well as the communalities $\left(\mathrm{h}^{2}\right)$ across the two functions for each variable were presented in Table 6 . Looking at the Function 1 coefficients, relevant predictor (called "Covariates") variables were primarily contributed by the farm size $\left(r_{s}=0.837 ; \quad r_{s}^{2}=70.06\right)$ and household size ( $\left.r_{s}=0.637 ; r_{s}^{2}=40.58\right)$ along with education $\left(r_{s}=0.457 ; \quad r_{s}^{2}=20.88\right)$ resulted in secondary contribution to the synthetic predictor variables, which was supported by squared structure coefficients. These socio demographic characteristics were also tending to have the larger canonical function coefficients. Furthermore, all of these variables' structure coefficients had the same sign, indicating all are positively related.

Regarding criterion (called "Dependent") variable set in function 1 , annual net family income variable $\left(r_{s}=0.813 ; r_{s}^{2}=66.10\right)$ contributes primarily to the synthetic criterion variable whereas, the capital available for crop production $\left.\quad r_{s}=0.785 ; \quad r_{s}^{2}=61.62\right)$ resulted in secondary contribution. As the structure coefficients (bivariate correlation between an observed variable and a synthetic variable) for both the criterion variables were positive and were positively related to all of the socio demographic characters of the farmers. These results were generally supportive of the theoretically expected relationships between economic and demographic characters, and Function 1 was labeled as "socio-demographic attachment". Moving to Function 2, the coefficients in Table 6, suggests that the only predictor variables of relevance were education $\left(r_{s}=\right.$ - 
$\left.0.559 ; r_{s}^{2}=31.25\right)$ and occupation $\left(r_{s}=\right.$ $\left.0.707 ; r_{s}^{2}=49.98\right)$, the farm size $\left({ }_{s}=0.394\right.$; $\left.r_{s}^{2}=15.52\right)$ was less so for the later. These socio demographic characters were inversely related on this function. As for attachment, capital available for crop production $\left.{ }^{r_{s}}={ }_{0.619 ;}{ }_{r_{s}^{2}}^{2}=38.32\right)$ was now the dominant criterion, along with annual net family income $\left.{ }^{r_{s}}={ }_{-0.582 ;} r_{s}^{2}=33.87\right)$. These attachment variables were also inversely related. Looking at the structure coefficients for the entire function, annual net family income was positively related to education and occupation. Capital available for crop production attachment had the opposite pattern with education and occupation, but having positive association with the farm size (ha.). Given the nature of these variables, this function was labeled as "socio-demographic detachment".

The last column in the Table 6 enlists the communality coefficients $\left(h^{2}\right)$, which represent the amount of variance in the observed variable that was reproducible across the functions. Note that these were simply the sum of the variable's ${ }^{r_{s}^{2}}$ s.

Table.1 Summary statistics of the socio economic and demographic characteristics of the farm households $(\mathrm{n}=600)$

\begin{tabular}{|l|c|c|c|c|c|}
\hline $\begin{array}{l}\text { socio economic and demographic } \\
\text { characteristics }\end{array}$ & Units & Mean & Std. Dev & Min & Max \\
\hline Annual net family income & Rs. & 42729 & 55424 & 129 & 511586 \\
\hline $\begin{array}{l}\text { Capital available for crop } \\
\text { production }\end{array}$ & Rs. & 23008 & 44818 & 110 & 64284 \\
\hline Work on farm by family & $\%$ & 22.66 & 27.58 & 0 & 85 \\
\hline Work on farm by famer & $\%$ & 77.34 & 31.08 & 0 & 100 \\
\hline Farmers' age & Years & 49.30 & 1.65 & 18 & 74 \\
\hline Household size & No. & 6.17 & 3.08 & 1 & 25 \\
\hline Males & No. & 3.28 & 1.77 & 0 & 16 \\
\hline Females & No. & 2.90 & 1.78 & 0 & 13 \\
\hline Earners in the family & No. & 2.48 & 1.40 & 0 & 8 \\
\hline $\begin{array}{l}\text { Labour Force Participation Rate } \\
\text { (LFPR) }\end{array}$ & $\%$ & 41.26 & 9.74 & 0 & 100 \\
\hline Members in crop production & No. & 1.96 & 1.30 & 0 & 8 \\
\hline Members in non-crop production & No. & 0.71 & 1.12 & 0 & 7 \\
\hline Family education & Score & 8.74 & 5.57 & 0 & 48 \\
\hline Children & No. & 0.88 & 1.14 & 0 & 8 \\
\hline Youth & No. & 0.64 & 0.91 & 0 & 5 \\
\hline Adults & No. & 4.05 & 2.03 & 0 & 17 \\
\hline Old persons & No. & 0.60 & 0.73 & 0 & 3 \\
\hline Land holding size & Ha. & 1.50 & 1.06 & 0.01 & 8.27 \\
\hline
\end{tabular}

Source: Computed based on the cost of cultivation survey data for the block year (2008-11) 
Table.2 Socio-economic and demographic categorical variables of the farm households $(n=600)$

\begin{tabular}{|c|c|c|c|}
\hline Variable & Category & Percent & Mode \\
\hline \multirow[t]{4}{*}{ Age group } & $<20$ years $=1$ & 0.17 & \multirow[t]{4}{*}{3} \\
\hline & $21-40$ years $=2$ & 22.67 & \\
\hline & $41-60$ years $=3$ & 55.50 & \\
\hline & $>60$ years $=4$ & 21.67 & \\
\hline \multirow[t]{2}{*}{ Gender } & Male $=1$ & 53.08 & \multirow[t]{2}{*}{1} \\
\hline & Female $=2$ & 46.92 & \\
\hline \multirow[t]{3}{*}{ Marital status } & Unmarried $=1$ & 3.00 & \multirow[t]{3}{*}{2} \\
\hline & Married $=2$ & 96.17 & \\
\hline & Widow $=3$ & 0.83 & \\
\hline \multirow[t]{5}{*}{ Land holding } & Marginal $=1$ & 24.50 & \multirow[t]{5}{*}{2} \\
\hline & Small $=2$ & 43.83 & \\
\hline & Semi-medium $=3$ & 27.67 & \\
\hline & Medium $=4$ & 3.67 & \\
\hline & Large $=5$ & 0.33 & \\
\hline \multirow[t]{4}{*}{ Education } & Illiterate $=0$ & 16.67 & \multirow[t]{4}{*}{2} \\
\hline & Primary=1 & 26.17 & \\
\hline & Secondary $=2$ & 47.00 & \\
\hline & Post Secondary $=3$ & 10.17 & \\
\hline \multirow[t]{3}{*}{ Occupation } & Crop Production=1 & 90.17 & \multirow[t]{3}{*}{1} \\
\hline & Non-crop agriculture $=2$ & 0.50 & \\
\hline & Other Services $=3$ & 9.33 & \\
\hline \multirow[t]{4}{*}{ Family size } & Small $=1$ & 12.50 & \multirow[t]{4}{*}{2} \\
\hline & Medium $=2$ & 52.33 & \\
\hline & Large $=3$ & 22.50 & \\
\hline & Very Large $=4$ & 12.67 & \\
\hline
\end{tabular}

Source: Computed based on the cost of cultivation survey data for the block year (2008-11) 
Table.3 Varimax rotated component matrix of exploratory factor analysis

\begin{tabular}{|l|c|c|c|c|c|c|c|}
\hline Socio-demographic variables & \multicolumn{7}{|c|}{ Factor loadings } \\
\cline { 2 - 7 } & $\mathbf{1}$ & $\mathbf{2}$ & $\mathbf{3}$ & $\mathbf{4}$ & $\mathbf{5}$ & $\mathbf{6}$ & $\mathbf{7}$ \\
\hline Household size & $\mathbf{. 9 7 6}$ & .106 & .054 & .054 & .005 & .009 & .122 \\
\hline Family size & .904 & .091 & .032 & .084 & .003 & -.003 & .128 \\
\hline No. of females & .852 & .053 & -.105 & -.014 & .000 & .098 & .247 \\
\hline No. of males & .843 & .131 & .199 & .108 & .009 & -.082 & -.036 \\
\hline No. of adults & .811 & .211 & .292 & .071 & .044 & -.054 & -.198 \\
\hline Family education & .731 & .464 & .090 & .028 & .139 & -.061 & .168 \\
\hline No. of children & .586 & -.129 & -.164 & -.142 & -.027 & .180 & .309 \\
\hline No. of youth & .559 & -.017 & -.315 & -.064 & -.057 & -.032 & -.113 \\
\hline Farm size (ha.) & .195 & .874 & .017 & .138 & -.166 & .024 & -.016 \\
\hline Land category & .208 & .864 & .017 & .147 & -.164 & .025 & .007 \\
\hline LFPR (\%) & -.329 & -.080 & $\mathbf{. 8 3 4}$ & .065 & -.052 & .003 & -.109 \\
\hline Work on farm by family (\%) & .312 & -.002 & .637 & .038 & -.086 & -.023 & .390 \\
\hline No. of earners & .613 & .120 & .629 & .135 & .132 & .008 & -.135 \\
\hline $\begin{array}{l}\text { Members involved in Crop } \\
\text { Production }\end{array}$ & .527 & .112 & .570 & .135 & -.450 & .053 & -.035 \\
\hline Age group & & & & & & & \\
\hline Actual age & .026 & .079 & .057 & $\mathbf{. 9 4 4}$ & -.042 & .067 & .110 \\
\hline Occupation & .032 & .104 & .101 & .935 & -.034 & .068 & .055 \\
\hline Work on farm by farmer (\%) & -.077 & -.098 & -.083 & -.033 & $\mathbf{. 8 2 0}$ & .047 & .049 \\
\hline $\begin{array}{l}\text { Members involved in non-crop } \\
\text { production }\end{array}$ & .017 & .098 & .106 & .039 & -.726 & -.008 & -.119 \\
\hline Gender & & & & & & & \\
\hline Marital Status & -.086 & .042 & .128 & -.075 & -.005 & $\mathbf{. 8 5 1}$ & .060 \\
\hline Education & .112 & -.062 & -.141 & .264 & -.013 & .725 & -.138 \\
\hline No. of old Persons & -.075 & .564 & -.098 & -.209 & .237 & -.146 & .742 \\
\hline Eigenvalues & .248 & .081 & .060 & .331 & .015 & -.050 & .726 \\
\hline \% of Variance & 6.9 & 2.7 & 2.0 & 1.9 & 1.7 & 1.2 & 1.1 \\
\hline Cumulative \% of variance & 30 & 12 & 9 & 8 & 7 & 5 & 5 \\
\hline (\%) & 30 & 42 & 51 & 59 & 66 & 71 & 76 \\
\hline
\end{tabular}

LFPR-Labour Force Participation Rate; Extraction Method: Principal Component Analysis; Rotation method:

Varimax with Kaiser Normalization: Rotation converged in 9 iterations

Table.4 Factor loadings based on exploratory factor analysis (EFA)

\begin{tabular}{|l|l|c|}
\hline Factor & \multicolumn{1}{|c|}{ Variables } & Factor loading \\
\hline $\mathbf{1 .}$ & Household size & 0.976 \\
\hline $\mathbf{2 .}$ & Farm size & 0.874 \\
\hline $\mathbf{3 .}$ & Labour Force Participation Rate (LFPR \%) & 0.834 \\
\hline $\mathbf{4 .}$ & Farmers' age group & 0.944 \\
\hline $\mathbf{5 .}$ & Farmers occupation & 0.820 \\
\hline $\mathbf{6 .}$ & Gender & 0.851 \\
\hline $\mathbf{7 .}$ & Farmers education & 0.742 \\
\hline
\end{tabular}


Table.5 Dimension reduction analysis of canonical function variables

\begin{tabular}{|c|c|c|c|c|c|c|}
\hline Root No. & Wilks $\boldsymbol{\lambda}$ & F & Hypoth. df & Error df & Sig. of F & Eigenvalue \\
\hline $\mathbf{1}$ to $\mathbf{2}$ & 0.649 & 20.304 & 14 & 1182 & $<0.0001$ & 0.4034 \\
\hline $\mathbf{2}$ to $\mathbf{2}$ & 0.912 & 9.519 & 6 & 592 & $<0.0001$ & 0.0965 \\
\hline
\end{tabular}

Table.6 Canonical solutions for predicting socio economic status for function 1 and 2

\begin{tabular}{|c|c|c|c|c|c|c|c|}
\hline \multirow[t]{2}{*}{ Variables } & \multicolumn{3}{|c|}{ Function 1} & \multicolumn{3}{|c|}{ Function 2} & \multirow[t]{2}{*}{$h^{2}(\%)$} \\
\hline & Coef. & $r_{S}$ & $r_{s}^{2}(\%)$ & Coef. & $r_{S}$ & $r_{s}^{2}(\%)$ & \\
\hline $\begin{array}{l}\text { Annual net family } \\
\text { income }\end{array}$ & 0.644 & $\underline{0.813}$ & 66.10 & -0.818 & $\underline{-0.582}$ & 33.87 & $\underline{99.97}$ \\
\hline $\begin{array}{l}\text { Capital available for } \\
\text { crop production }\end{array}$ & 0.606 & $\underline{0.785}$ & 61.62 & 0.846 & $\underline{0.619}$ & 38.32 & $\underline{99.94}$ \\
\hline$R_{c}^{2}(\%)$ & & & 28.8 & & & 8.8 & \\
\hline Age group & -0.063 & 0.088 & 0.77 & -0.249 & -0.071 & 0.50 & 1.28 \\
\hline Gender & 0.011 & -0.039 & 0.15 & -0.115 & -0.079 & 0.62 & 0.78 \\
\hline Household size & 0.470 & $\underline{0.637}$ & 40.58 & -0.124 & 0.040 & 0.16 & 40.74 \\
\hline Education & 0.260 & $\underline{0.457}$ & 20.88 & -0.656 & $\underline{-0.559}$ & 31.25 & $\underline{52.13}$ \\
\hline Occupation & 0.219 & 0.096 & 0.92 & -0.568 & $\underline{-0.707}$ & 49.98 & $\underline{50.91}$ \\
\hline Farm size (ha.) & 0.692 & $\underline{0.837}$ & 70.06 & 0.534 & 0.394 & 15.52 & $\underline{85.58}$ \\
\hline $\operatorname{LFPR}(\%)$ & 0.082 & -0.157 & 2.46 & -0.021 & 0.071 & 0.50 & 2.97 \\
\hline
\end{tabular}

Note: Structure coefficients $\left(r_{g}\right)$ greater than $|0.45|$ are underlined. Communality coefficients $\left(h^{2}\right)$ greater than $45 \%$ are underlined. Coef=standardized canonical function coefficient; $r_{s}=$ structure coefficient; $r_{s}{ }^{2}=$ squared structure coefficient; $h^{2}=$ communality coefficient, $R_{e}^{2}=$ squared canonical correlation.

The communalities were analogous to communality coefficients in factor analysis and can be viewed as an indication of how useful the variable was for the solution. For emphasis, following a convention in many factor analyses, structure coefficients above 0.45 were underlined (Sherry and Henson, 2005) in Table 6. Communalities above 45 per cent are also underlined to show the variables with the highest level of usefulness in the model.

This study helps in proper monitoring of farmers' welfare and throw light on the estimation of the socio economic status of the farmers based on their demographic profile. Majority of the farmers were between 41-60 years of age, dominated with males, married and had household size of six members. Similarly, the farmers were educated and low income earners of less than Rs. 3500 per month. The socio demographic factors viz. household size, farmers age group, farm size, gender, labour force participation rate $(\%)$, occupation and farmers education were identified as the principal factors capable of influencing socio economic status of farm households in West Bengal. Among these factors farm size, level of education, household size and occupation were significant factors and capable of positively influencing the income levels of the farm households, results in improving the socio economic status. As significant relationship 
existed between education and economic status indicates more educated farmers visualize the problems of scientific agriculture and the scope of practicing new technologies for getting higher productions to improve their socio economic status. The study suggested improvements in different socio demographic indicators required for enhancing the economic status of the farm households.

\section{Acknowledgements}

The authors are grateful to the Department of Science and Technology- Innovation in Science Pursuit for Inspired Research (DSTINSPIRE), Govt. of India for encouraging and providing financial support for the research. The authors are also thankful to Department of Agriculture and Cooperation, Directorate of Economics and Statistics (CS Division), Ministry of Agriculture and Farmers Welfare for providing permission for utilization of cost of cultivation data.

\section{References}

Adegboye, M.A., 2016. Socio-economic Status Categories of Rural Dwellers in Northern Nigeria. Advances in Research. 7(2): 1-10.

Chand, R., and Gupta, M. C. 1966. A study of adopters of improved farm practices and their characteristics. Indian Journal of Extension Education. 4, 259-267.

Dey, A., Goswami, A., and Mazumdar, D. 2014. Adoption behavior of livestock farmers in Paschim Medinipore district of West Bengal, India. International Journal of Current Microbiology and Applied Sciences. 3(8): 666-672.

Government of India. 1980. Report of the Special Expert Committee on Cost of Production Estimates. Department of
Agriculture and Cooperation, Ministry of Agriculture.

Hotelling, H., 1935. The Most Predictable Criterion. Journal of Educational Psychology. 26, 139-142.

Johnson, R. A., and Wichern, D. W. 2007. Applied Multivariate Statistical Analysis $\left(6^{\text {th }}\right.$ Eds). Prentice-Hall of India Pvt. Ltd., New Delhi. Pp. 273359.

Kinnear, P., and Gray, C. 2010. PASW 17 Statistics Made Simple. Psychology Press, New York.

Krishna, A.B., 2012. Bt technology: labour use pattern in cotton (A case study of Andhra Pradesh). Asian Journal of Research in Social Science and Humanities. 2(1): 25-28.

Oloruntoba, A., and Fakoya, E. O. 2000. Socio-Economic Indicators of AdultFemales in Rural Communities of Nigeria. Journal of Extension Systems. 3(18): 48-57.

Onumadu, F.N., and Osahon, E. E. 2014. Socio-Economic Determinants of Adoption of Improved Rice Technology by Farmers in Ayamelum Local Government Area of Anambra State, Nigeria. International Journal of Scientific and Technology Research. 3(1): 212-215.

Samaun Safa, M., 2005. Socio-Economic Factors Affecting the Income of Small-scale Agroforestry Farms in Hill Country Areas in Yemen: A Comparison of OLS and WLS Determinants. Small-scale Forest Economics, Management and Policy. 4(1): 117-134.

Singha, A.K., Baruah, M. J., Bordoloi, R., Dutta, P., and Saikia, U. S. 2012. Analysis on influencing factors of technology adoption of different land based enterprises of farmers under diversified farming systems. Journal of Agricultural Sciences. 4(2): 139- 
143.

Sherry, A., and Henson, R. K. 2005. Conducting and Interpreting Canonical Correlation Analysis in Personality Research: A User-Friendly Primer. Journal of Personality Assessment. 84(1): 37-48.

Stewart, David W., 1981. Application and misapplication of factor analysis in marketing research. Journal of Marketing Research. 18, 51-62.

Suri, R.K., and Chhabra, T. N. 2009. Managing Human Resource: Techniques and Practices. Human Resource Planning and policies. Pentagon press. New Delhi. Pp. 81.

Tabachnick, B.G., and Fidell, L. S. 2007. Using multivariate statistics ( $5^{\text {th }}$ Eds). Upper Saddle River, NJ: Allyn and Bacon/Pearson Education. Pp. 607635.
Thompson, B., 1991. A primer on the logic and use of canonical correlation analysis. Measurement and Evaluation in Counseling and Development. 24(2): 80-96.

Ven, D.B.J., 2013. Socio-economic factors affecting adoption of improved agricultural practices by small scale farmers in South Africa. African Journal of Agricultural Research. 8(35): 4490-4500.

Williams, B., and Brown, T. 2010. Exploratory factor analysis: A fivestep guide for novices. Australasian Journal of Paramedicine. 8(3): 1-11.

Yvas, S., and Kumaranayake, L. 2006. Constructing socio-economic status indices: how to use principal components analysis. Health Policy Plan. 21, 459-468.

\section{How to cite this article:}

Samba Siva, G., D.S. Gupta and Debobrata Ghosh. 2019. Multivariate Approaches to Measure the Association among Socio-Economic and Demographic Factors of the Farm Households in West Bengal. Int.J.Curr.Microbiol.App.Sci. 8(06): 1280-1290.

doi: https://doi.org/10.20546/ijcmas.2019.806.155 